
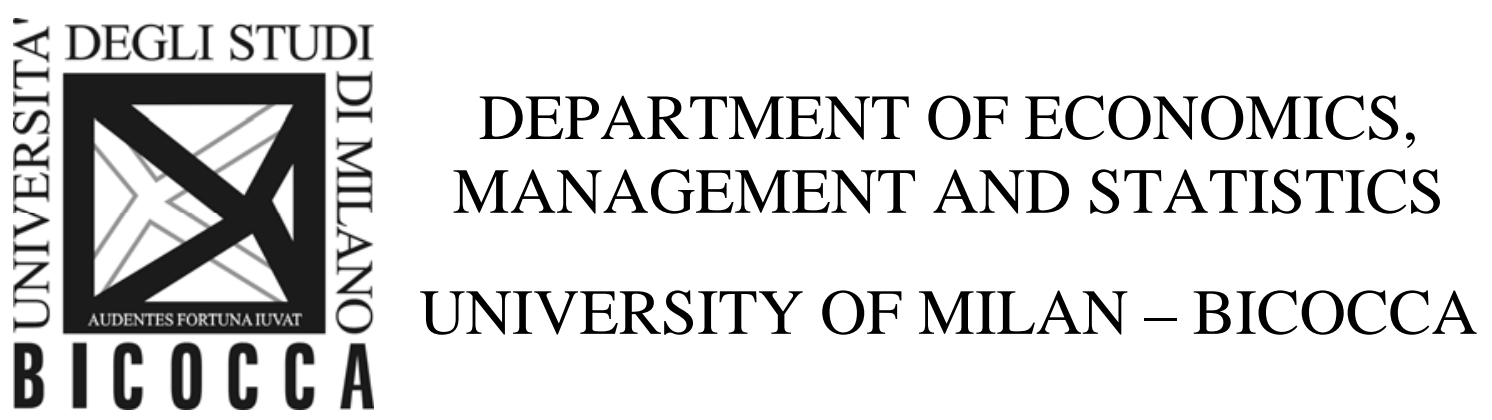

DEMS WORKING PAPER SERIES

\title{
What kind of Welfare State do you prefer? An experiment on framing the social insurance scheme
}

Francesco Farina, Stefania Ottone, Ferrucio Ponzano

No. 295 - March 2015

Dipartimento di Economia, Metodi Quantitativi e Strategie di Impresa Università degli Studi di Milano - Bicocca 


\title{
What kind of Welfare State do you prefer? An experiment on framing the social insurance scheme
}

\author{
Francesco Farina \\ University of Siena
}

Stefania Ottone*

University of Milan-Bicocca
Ferruccio Ponzano

University of Eastern-Piedmont

\begin{abstract}
.
A real-effort experiment is conducted in order to detect preferences for one of three different models of Welfare State characterized by different schemes of tax-and-transfers. Experimental subjects have to choose (both under and without veil of ignorance concerning their position in the society created in the lab) among: a) a baseline proportional scheme, where the State is neutral with respect to risk heterogeneity; b) an actuarially-fair scheme where low-ability and low-earnings subjects bear individual full responsibility for risk exposure; c) a progressive scheme where mutual risk insurance spreads risk across all subjects, so that low-ability and low-earnings individuals are compensated. The aim is to investigate how subjects posit with respect to the task performed by the Welfare State, which is the interaction between inequality of opportunity and income inequality facing low-ability and low-earnings individuals due to their relatively higher risk exposure. Our most relevant finding is that preference is not much motivated by a justice principle, but mainly by the expectation on one's own position in the society.
\end{abstract}

Key words: Welfare State, insurance, redistribution, proportional system, actuarially-fair system, progressive system

JEL CLASSIFICATION: C9, D31, D63, H26

\footnotetext{
* Corresponding author. Department of Economics, Management and Statistics and EconomEtica and NeuroMi, University of Milano-Bicocca. E-mail: stefania.ottone@unimib.it
} 


\section{Introduction}

In the era of globalized markets, the idea of Welfare institutions providing income and in-kind support to "disadvantaged" individuals is under scrutiny, both in economic literature and in the democratic deliberation by majority voting of advanced countries. The Welfare State - the public institution providing social protection which has been built in the past century by the advanced countries - is often portrayed as essentially designed to promote income redistribution. Actually, the nature of the Welfare State is more differentiated. Some institutions are directly devoted to "pure" redistribution to deprived people (e.g., free meals, food stamps, and shelters). A series of programmes organizing monetary transfers and in-kind services are designed to establish the "public good" of solidarity by giving relief to the poor and dealing with the "distaste" of society for excessive inequality (Thurow, 1971). Other institutions are devoted to mutual risk insurance through the provision of public and merit goods, in order to address the heterogeneity across individuals, vis-à-vis the risk of a negative event. Depending on the specific features of each country's scheme of tax and transfers, these institutions indirectly operate Pigou-Dalton redistribution from the rich to the low-earnings taxpayers, as these latter subjects pay low tax contributions but normally benefit much from monetary transfers and in-kind services.

The overall well-being of a person is usually computed as the (weighted or unweighted) sum of independent scores, each one measuring a single dimension of that person's well-being. Then, the indicators of personal well-being implicitly assume substitutability of beneficial or detrimental changes across dimensions. However, a series of studies conducted on OECD countries report that the different dimensions reinforce each other, thus suggesting the presence of complementarity across the contribution of each dimension to the overall well-being ${ }^{1}$. Given overwhelming evidence of these kinds of negative externalities, the reshuffling across deciles of the earnings distribution makes the risk pooling organized by public agencies a powerful mechanism through which not only income inequality shrinks but also the distance of opportunities of well-being across individuals is reduced. The Pigou-Dalton transfer from the market income of the low-risk-exposed subjects (the rich) to the disposable income of the high-risk-exposed subjects (the poor) alleviates disadvantaged conditions of these latter individuals, thus contributing to raise their chances of well-being in crucial dimensions such as health and education.

\footnotetext{
1 " (T)he distribution of well-being across individuals (...) is especially important when there are disparities in achievements across population groups and when these are correlated across dimensions (e.g. when the likelihood of earning a low income is correlated with low educational achievement, poor health status, poor housing, etc.). (OECD, 2011, p.18)." A sizeable incidence of cross-correlation of poverty and social exclusion has been proved too: "Multivariate studies relying on different controls suggest that the probability of being deprived is higher for: persons who are young; unemployed or with weak ties to the labour market; poorly-educated; living alone or as a lone parent; disabled; immigrants; or receiving welfare benefits (OCED, 2008, p.186)."
} 
Therefore, Welfare institutions stay at the cross-road between income inequality and inequality of opportunity, as their insurance and redistribution functions help disadvantaged individuals to get equal chances at the starting gate of the life race. As suggested by Amartya Sen:

“There may be some accentuation of inequality due to the 'coupling' of income inequality and unequal advantages in converting incomes into capabilities, the two together intensifying the problem of inequality in terms of opportunity - freedom.” (A.K.Sen, 1993, p. 536).

Therefore, the two objectives of the Welfare State - to reduce inequality of opportunity by providing mutual risk insurance, and to reduce income inequality by providing "pure redistribution" - are tightly interwoven (Roemer, 2000; Roemer et al., 2003). Any variation in one of the two crucial indicators of well-being is bound to impinge upon the evolution of the other one.

This problem has been partly dealt with during the XX century. Social insurance and redistributive institutions were deployed by governments, as many dimensions of well-being were perceived as those in which either rational behaviour, or the market method of coordination, fail. Depending on various historical processes, and because of the need to preserve socio-economic stability, during the past century in many advanced economies these failures have been tackled through the extension of State intervention. The centralized coordination implemented by the State substituted for the decentralized coordination performed by market forces in order to shield individuals from the exposure to negative events and provide relief to poverty. To a different degree in different countries, the tax levy aimed to fund the provision of public and merit goods has soared.

As for the first kind of failure, dealing with bounded rationality, when formulating a low demand for tertiary education (or by even waiving secondary education) many subjects suffer from myopic behaviour, as they do not take into account the long-term consequences of low education on the length of unemployment spells and, more generally, on their expected lifetime average earnings. As for the second, dealing with the "incomplete markets" hypothesis, in many countries subjects with a low income and a high risk of bad health are fully covered by public provision of health services, while they would be penalized by private insurance companies refusing to offer them health care contracts. Similarly, an intergenerational solidarity mechanism is embedded in the PAYGO pension systems, as young workers fund the public pension scheme providing transfers for the retired people.

Throughout the second half of the past century, the self-aggravating interaction between inequality of opportunity and income inequality has been mitigated by the construction or the expansion of Welfare institutions. Yet, in recent decades the view has gained momentum that the size of the Welfare State has become too large for the incentive to invest and to risk, by entrepreneurs and 
workers respectively, to be preserved. Many governments have started pursuing Welfare reforms meant to reduce social protection coverage, by shrinking taxation supporting social expenditures and by switching to "means-test" social protection. The overall strategy consists in complementing public institutions of mutual risk sharing with the private provision of social protection (e.g., private pension funds, quasi-market health care firms, the organization of privately-runned "welfare accounts", etc.) aimed at strengthening personal responsibility in coping with the microeconomic risks (e.g., the probability of bad health and/or low education) and the macroeconomic risks (e.g., the probability of long term unemployment, poverty).

This move from "mutual risk insurance" towards "individual responsibility" is transforming the organization of public institutions of social protection. Very briefly, the earnings' reshuffling across individuals through tax cut for the top incomes is reduced, and the amount of resources transferred to the middle class with lower-than-mean income is shrunk through eligibility by means-test, so as to limit redistribution to the amount needed to provide a safety net for the poor. In particular, the governments of some European countries have started coping with the "moral hazard" problem hampering the functioning of the labour market and implemented the so-called "workfare" social protection strategy. By protecting the unemployed worker instead of jobs that firms no longer consider rewarding, the design aims to reconcile the equity objective with the efficiency objective. The subsidy to the unemployed is conditioned on the inescapable commitment to strengthen their abilities through retraining programmes, and to accept the second offer by the public agency for labour of a new job albeit at a lower wage rate. Similarly, the skyrocketing cost of health care is forcing many governments to ask patients a monetary contribution to the provision of various health services, and has also accelerated the trend towards offering a more comfortable treatment at a higher price, which is meant to satisfying the desire of "freedom of choice" of mostly high-income subjects.

Finally, public pension agencies are increasingly in deficit. In many countries, pension transfers are computed on an average of the most recent yearly earnings, so that their yearly transfer to the retired, which is funded from the young generation's earnings, is often higher than the actualized value implied by their accumulated social contributions. Public pension transfers are more and more complemented by private pension payments (in many advanced countries, during the working age workers use part of their savings to buy shares of a pension fund). The expectation of further increases in the budget needed by the public pension system, mainly because of the continuous lengthening of life expectancy, contributes to strengthen the political pressure in favour of an "actuarially-fair" computation of pension transfers. Reforms of public pension schemes then point to the reduction of the distance of pension payments from the actualised value of a pension (i.e., the 
global amount accumulated by the retired when working is transformed by the public agency in annuities of pension payments on the basis of life expectancy at the moment of retirement). Also, private insurance companies are dismissing defined-benefit private schemes (that is the promise of an annual payment throughout the retirement period, whatever its length). In fact, just as public PAYGO schemes are suffering from the excessively generous pension contracts worked out by governments in the decades of high growth, private pension schemes are troubled by losses caused by a life expectancy which in advanced countries is rapidly increasing at an exponential rate.

Under the pressure of social scientists, and of influential opinion makers in the media, the public opinion of the advanced countries is rather divided with regard to these structural changes towards "individual responsibility". On the one hand, the view is increasingly shared that a small size of the Welfare State boosts growth, as low taxation is the best incentive for firms to invest and promote social welfare (Hassler et al. 2003). By the same token, the right to self-ownership of personal talents recommends that ability be appropriately rewarded, and a low generosity of Welfare transfers is reputed to maximize effort by workers (Alesina et al. 2001). The sustained labour demand fostered by high growth is bound to promote more equal earnings opportunity across the labour force; at the same time, a strong growth of fiscal revenues will allow the tax rates to remain small, so that a rising disposable income could put workers in the position to take personal responsibility in tackling risks and avoid that the firms' incentive to invest could be jeopardized by too high profit taxes (Alesina and Giuliano, 2009; Alesina et al. 2012).

On the other hand, the opposite view stresses that low-ability and low-income subjects are likely to bear a relatively higher exposure to risks, which is mainly connected to important dimensions of well-being such as health and education (for instance, the lower the income, the higher is the subject's probability to be under-educated and suffer from a precarious health). Since a soaring inequality of opportunity due to the worsening of health and education conditions raises the risk exposure of low-ability and low-income citizens, a large Welfare State is viewed as a guarantee that income distances would not be so large as to hamper the expectations of well-being across the population. A low household income level negatively impacts on the well-being of its members, possibly causing a low education level of the offspring as well as poor health conditions of parents and old relatives. In turn, these drivers of a shrinking well-being feedback on skill level and workers' capabilities, possibly further lowering the wage level and rising the exposure to the risk of unemployment and macroeconomic "vulnerability" in general (Wilkinson and Pritchett, 2009). Furthermore, a strong safety net against bad events, far from jeopardizing market incentives, could help in strengthening the propensity to work (Sinn, 1995). In this perspective, the objective of social 
protection institutions consists in the attempt to curb the causal link from low ability to low income to low opportunities, further diminishing earnings.

To more deeply understand the coherence between citizens' social preferences and the design of reforms currently implemented by governments, we perform a within-subject experiment in which we elicit preferences for different types of Welfare State. ${ }^{2}$

By focusing attention on alternative models of tax-and-transfers system to finance the Welfare State, we test people's preferences for different schemes of social protection. The design is devised to simulate the functioning of the redistribution operated by the tax-and-transfers system. The protocol is meant to incentivize the experimental subjects to address the link between ability and risk exposure in forecasting their disposable income. In order to collect this information, we reproduce a small society in the lab where: 1) subjects are grouped in three stylized classes (the rich, the middle class and the poor) on the basis of their performance in a real-effort activity; 2) income and risk are assigned according to the class; 3 ) subjects have to choose among three different models of Welfare State (WS) both before and after being informed about their position in the society created in the lab. Since we aim at mimicking the various schemes of tax and transfers implemented in advanced countries, each of them is characterized by a different redistributive impact. More specifically, we present a very parsimonious scheme for each of three contracts: A) Neutral WS (Proportional); B) Individualistic WS (Actuarially-fair); C) Prioritarian WS (Progressive). The label of these Welfare contracts indicates the extent to which the WS copes with the subject's risk exposure, starting from the earnings accruing to him according to the ability shown in performing the task. The definitions in parenthesis synthesize the analytics of the tax-and-transfers scheme, namely the impact on disposable income of the tax rate assigned to each level of market income.

Our most relevant finding is that people's preference for a particular state may be explained in terms of self-interest. In other words, generally people choose the contract that is most advantageous according to their expected/actual position in the society created in the lab.

\section{Experimental design: a society in the lab}

In this experiment, we try to reproduce a proxy of a small society in the lab where subjects belong to a specific class according to their wealth. As in a real society, they are asked to pay for taxes and they are provided a public good by the State. Obviously, we do not reproduce all the complex dynamics that characterize a real society. Instead, we focus on the relation between subjects and their State. This simplification, where the variables of interest are controlled, should help us to better understand what drives people's preference for a specific taxation system. Our main goal was

\footnotetext{
${ }^{2}$ While this paper has been conducted with Italian subjects, we plan to extend the research to other European countries.
} 
to make the design extremely parsimonious and focus on the basic facts concerning the Welfare State, so that the experiment could be replicated in other advanced countries for the purpose of inter-cultural comparison.

In the following sections we will provide a detailed description of the characteristics of this experimental society.

\subsection{The classes}

We have designed the experiment as a real-effort activity, where participants are asked to earn their initial income by performing an ability test. In particular, they are given thirty Raven's matrices and they are asked to solve as many as they can. ${ }^{3}$ Participants are then grouped into three categories on the basis of their relative scores. That is, given $n$ subjects participating, the best $n / 3$ participants belong to the first category (the rich); the second $n / 3$ belong to the second category (the middle class); the worst $n / 3$ belong to the third category (the poor). ${ }^{4}$ Depending on the category in which each participant is included as an effect of his performance, subjects are given an initial endowment and they are exposed to a "low", "medium", or "high" risk of suffering a "bad event".

The scheme works as follows. The rich are endowed with a gross income of 300 tokens and they have a probability equal to $40 \%$ to loose 80 tokens. The middle class subjects are endowed with a gross income of 200 tokens and they have a probability equal to $50 \%$ to loose 80 tokens. The poor are endowed with a gross income of 100 tokens and they have a probability equal to $60 \%$ to lose 80 tokens 5 .

\subsection{The contracts}

As said above, we call contract A "Neutral", contract B "Individualistic" and contract C "Prioritarian". The three taxation schemes work as follows. In the Neutral State we have a proportional taxation. We impose a $30 \%$ tax rate for each subject. The Individualistic State is the "actuarially-fair" one, where taxation is directly proportional not to income but to the subject's risk exposure, so as to probabilistically avoid redistribution from the rich to the poor (it is assumed a

\footnotetext{
${ }^{3}$ It is a nonverbal group test used to measure cognitive abilities. It is independent of linguistic and mere factual knowledge. The test consists of a series of multiple choice questions. For each test item, the subject is asked to choose the missing element that completes a pattern. Patterns are presented in the form of $3 \mathrm{X} 3$ matrices. See Figure 1 for an example of Raven's Matrix.

${ }^{4}$ Obviously, we do not use terms like "rich", "poor" or "Welfare State" in the instructions. We use neutral terms.

${ }^{5}$ We obviously know that, in a society, the distribution of income is a continuum. Nevertheless, in order to simplify our environment, we choose to group subjects into three categories with a given income ratio among them. This ratio - the rich earn three times what the poor earn and the middle class twice - is inspired by the real distribution of income in the North of Italy. In fact, according to the data of the Ministry of the Economy, the income of the $75^{\text {th }}$ percentile is three times the income of the $25^{\text {th }}$ percentile and the income of the $50^{\text {th }}$ percentile is twice the income of the $25^{\text {th }}$ percentile (see Acciari and Mocetti, 2013, p. 31, figure 4).
} 
strongly negative correlation between the subject's earnings level and his exposure to the risk of a negative event). Since this scheme is meant to prevent Welfare institutions to spoil market incentives and induce subjects to moral hazard behaviour, the disposable income has to fully reflect the reward of their performance. The payment for this contract consists of two elements: a proportional component with a $10 \%$ tax rate and a part that is directly correlated to the risk subjects face to lose the 80 tokens.

Finally, the Prioritarian contract implements progressive taxation. Contrary to the previous scheme, the objective is to take into full account the negative impact of low earnings, stemming from a poor performance in the task, on the overall distribution of opportunities (the assumption is that low ability implies a high probability of a negative events). The rich are then taxed at a $35 \%$ rate, the middle-class people are taxed at a $30 \%$ rate and the poor are taxed at a $15 \%$ rate $^{6}$.

In each Welfare State -whatever the taxation scheme - the tax revenue is used to implement two functions. The first one is to fully refund people that lose a part of their income. ${ }^{7}$ Secondly, the remaining part of the tax revenue is equally redistributed among all participants. What do these contracts represent from the viewpoint of standard economic theory?

Contract A is "Neutral", as the scheme preserves the right of the individual to be taxed in proportion to his income level (that is, the reward connected to the experimental subject's ranking in performing the task in the lab). The rationale is that the State does not concern itself with possible failures embedded in the functioning of the market economy, that is the deviations from the "correct" earnings distribution according to each individual's ability, which may be caused by myopic behaviour or incomplete markets preventing horizontal equity in risk insurance. The earnings distribution then abides by the Aristotle principle of proportionality between marginal factor productivity and earnings (Konow, 2000 and 2001), so that his disposable income probabilistically replicates the standard equivalence between earnings and the productive contribution of a worker. This contract can be thought of as the one signed with citizens by the "paternalistic State" willing to provide social insurance by levying proportional taxation, but not taking into consideration heterogeneity across citizens in terms of their different probability of "disadvantaged" conditions, stemming from their different exposure to negative events. The tax rate is $30 \%$ of market income for each subject

\footnotetext{
${ }^{6}$ The choice of these tax rates is not random. In particular, the median tax rate in our experiment, equal to $30 \%$ - is very close to the real marginal tax rate paid by Italian employees with a gross income between 8000 and 55000 euro (Paladini, 2011). Moreover, these tax rates allow maintaining the same distance, in terms of tax contribution, between the rich and the middle class and between the middle class and the poor in each contract.

${ }^{7}$ Please notice that, since a function of the Welfare State is full insurance, the individual effect of losing 80 tokens is exclusively indirect: a reduction of the pot available for redistribution.
} 
Contract B is "Individualistic" as, by ensuring the actuarially fair "price", this contract is meant to preserve self-ownership, both in the sense of the right to keep the reward of one's ability and of each individual being responsible for protecting himself against his own risk exposure without expecting the financial support of "such a thing called society". In particular, imperfect information about individual characteristics prevents the assessment of personal responsibility and suggests to protect incentives by retreating from redistributive policies and letting individuals fully bear the consequences of their choices (Fleurbaey, 2008). Therefore, this second contract does not take into account the possible perverse consequences of correlation across dimensions of life in case of negative shocks to well-being, and just sets the price equal to the probabilistic cost of a bad event, thus avoiding any redistributive effect. The objective of efficiency is best served by an insurance scheme imposing the direct proportionality of the taxation borne by each individual to his own degree of risk of incurring in negative events. The equity principle embedded in this contract aims to preserve the income distribution determined by market forces, while no weight is attributed to each subject's income-dependent risk exposure. The tax-and-transfers system is then oriented to an "actuarially-fair" Welfare State, to prevent that the high-risk individuals' greater use of the Welfare institutions be paid by the low-risk individuals (Krawczyk, 2010). In this "individualistic" vision of the Welfare State, the low-income individuals - that is those who are more likely to gain from the Welfare institutions, as in probabilistic terms for them benefits are bound to exceed costs - are those who must fully bear the cost of their choices.

Contract C ("Prioritarian") devises the tax-and-transfers system according to the theoretical view that higher risk exposure must be compensated by giving priority to the needs of the "worst-off" individuals (Rawls, 1971). More precisely, contrary to the previous scheme, the Prioritarian view takes for granted both that in the real world individuals are mostly not responsible for exhibiting a low ability in their work performance ${ }^{8}$ and that markets fail in achieving horizontal equity. This latter circumstance materializes once the two following conditions both apply: (i) The individual who shows a low ability in carrying out his task in his workplace could not be completely responsible for his poor work performance because he suffers from bad luck ${ }^{9}$ (e.g. a poor educational record, due to birth in a deprived household and/or to negative externalities such as neighbour and peer effects); (ii) Very high premiums are usually charged by private companies for the contracts offered to high-risk - who are in addition low-earnings - individuals. Given that the

\footnotetext{
${ }^{8}$ According to Rawls, personal talents do not belong to individuals because they did not merit them; talents are to be redistributed through monetary compensation accruing to individuals poorly endowed with talents.

${ }^{9}$ Many economists and philosophers belonging to the "distributive justice" literature maintain that inequalities induced by differential luck are to be compensated. Among others, Ronald Dworkin argued that a sharp distinction is to be made between a critical condition of life if it is the effect of "option luck" (that is, it is caused by inappropriate behaviour: e.g., a cancer of the heavy smoker) or it is just the consequence of "bad luck", the wrong ticket in the lottery of life (see Dworkin, 2000).
} 
functioning of the market for insurance contracts is unable to equalize the distribution of opportunities across subjects, the lack of horizontal equality may further increase inequality of earnings.

This amounts to entrusting to the State the task to take into account possible negative consequences on the multidimensional well-being of low-earnings subjects caused by a high degree of risk exposure for which these individuals are not responsible. To mimic this function often assigned to the modern Western Welfare State, the design of contract C allows the "disadvantaged" individuals to bear a lower burden of the cost of the Welfare State in terms of the difference between taxes paid ex ante and expected benefits to be obtained ex post. The fulfilment of this latter objective unavoidably implies redistribution.

In our experimental setting, contract A functions as the baseline contract corresponding to the justice principle of "proportionality", where the causality nexus highlighted by Sen $^{10}$ - from inequality of income to inequality of opportunity and viceversa - is ignored. This Welfare State contract can be taken as mimicking the market as a "neutral" coordination mechanism. More precisely, this contract ignores the view that inequality of income, depending on ability heterogeneity across workers, could provoke a higher risk exposure to a loss in well-being thus magnifying the inequality of opportunity. Since the market is considered as a "value-free" institution, no equity principle aimed to manipulate the outcome produced by market forces should be introduced into the tax-and-transfers scheme.

The other two contracts instead endorse extremely different theoretical positions about individual responsibility in the ability to exploit chances for well-being. In fact, opposite stances are held with respect to the link between ability level, income level, and risk exposure, each of which ends up in advocating a very different tax-and-transfers scheme.

As for the "Individualistic" contract, risk insurance must be free of redistribution from the rich to the poor. To exemplify, in the case of health services the price of public provision should equalize its cost of production times the probability of the bad event, the price of public education should equalize the actualized value of expected future earnings, the pension transfer should equalize the present value of the subject's contributions accumulated during his working years. As for the "Prioritarian" contract, inequality of income is assumed to strongly interact with inequality of opportunity. Consequently, individuals suffering from low ability and low earnings deserve to be compensated for their "disadvantage" in exploiting opportunities for well-being. The rationale of this Welfare contract is then to probabilistically carry out redistribution by means of progressive taxation, to prevent complementarity across dimensions of well-being from severely worsening the

\footnotetext{
${ }^{10}$ A comprehensive appraisal of the theoretical contribution of A.K. Sen to these central questions can be found in his "The Idea of Justice" (see Sen, 2009).
} 
well-being of the "disadvantaged" individual. The computation of the balance between costs (taxes) and benefits (monetary transfers plus avoided expenses) across individuals participating in public institutions of risk pooling shows the redistributive impact of in-kind services ${ }^{11}$. Once the price of the contract is negatively linked to risk exposure, the overall redistribution stemming from monetary transfers plus the imputed value of in-kind services benefits the low-income individuals and penalises the rich taxpayers. Therefore, the higher risk exposure of low-income individuals is $a$ priori - that is, through progressive taxation - compensated.

In our experiment we designed the three contracts in a very simple way. In addition to the analytical advantage of devising a very parsimonious scheme, this delivers the practical advantage of reducing experimental subjects' cognitive mistakes. However, the relation between the classes and the contracts allows us to identify, in most cases, self-interest and ideological motivations behind people's choices: rich and poor are clearly advantaged by a specific contract - the Actuarially-fair and the Progressive contract respectively - while the middle class is indifferent. In section 6 we will treat in details this issue.

\subsection{The voting scenarios}

In each session, the experimental subjects participate in two voting rounds. In the first voting round they have to rank the three contracts assigning three points to the most preferred contract, two to the second one and one to the worst option. In this scenario, people do not receive any information about their performance and the category they belong to. We call this round 'Veil of Ignorance' condition (VOI). In the second voting round, people are asked to re-rank the contracts after being informed about their position in the society (NO_VOI condition).

At the end of the experiment, the contract that receives the highest score in the NO_VOI condition is actually implemented (Borda-count procedure).

During the experiment we treat the two scenarios as two separate treatments. This means that, at the beginning no participant knows that the experiment consists of two rounds and that they will be allowed to vote twice. In other words, experimental subjects are instructed round by round. This implies that, under the VOI condition, participants are given instructions concerning that round only and that they are not informed about the existence of another round. This choice is due to the fact that we did not want people's choices in the VOI scenario to be affected by the possibility of a further voting round.

\footnotetext{
${ }^{11}$ The estimation of the value of in-kind services, performed through the method of the insurance value (the allocation of an equal amount to every individual sharing the same characteristics: age, health, and gender) results in a substantial reduction in inter-personal income inequality (see Marical et al., 2006).
} 


\section{The procedure}

This is a laboratory experiment, where decisions are recorded through the computer. Instructions are read by participants on their computer screen, while an experimenter reads them out loudly. The experiment is programmed and conducted with Z-tree (Fischbacher, 2007). ${ }^{12}$

Participants enter the laboratory and take a seat in front of a computer. They are immediately asked to switch off their mobiles and to stop talking to their colleagues. First of all, instructions concerning the task to be carried out are presented. Subjects are informed about the nature of the task, and they are provided an example of Raven's matrix in order to be familiar with their activity. After that, participants are instructed on the way classes are created, how the risk of losing money is simulated in the lab, on the characteristics of the three contracts and on the rules of the first voting round (VOI condition). A sheet of paper with all this information is handed out too. At this point, a set of control questions is asked in order to be sure that players understood the rules of the game when taking decisions.

Before performing the task, we ask players to predict the category they will belong to - we pay them if the prediction is correct. At this point, subjects start to perform the task. At the end of that they participate in the first voting round (VOI condition). Then, they are informed about the category they belong to and we ask them to re-rank the three Welfare contracts (NO_VOI condition).

At the end, they cast a ten-face dice. If the number is lower than five (six, seven) for subjects that belong to the first (second, third) category 80 tokens are lost. On the basis of a Borda-count electoral system, the computer announces the preferred Welfare State and each participant can view his own payoff on his computer screen. Finally, before receiving their payment, subjects fill in a socio-demographic questionnaire. A scheme of the experimental design is provided in Figure 2.

The value of each token was 0.08 euro. The correct prediction for the category was paid 1 euro and the questionnaire 3 euro. The average gain was 15 euro. There was no show-up fee. The reason is that it would represent a sort of guaranteed wage, which is neither suitable nor desirable for our research question. In fact, there is no reason to introduce a guaranteed wage in a Welfare State where it is already the result of a specific process.

The entire experiment preserved anonymity among participants.

\section{The payoffs}

Given the structure of the experiment, each subject's payoff $\left(\mathrm{P}_{i}\right)$ consists of four elements: the amount of tokens earned during the treatment $\left(E_{i}\right)$, money earned in case of correct prediction of

\footnotetext{
${ }^{12}$ The experiment has been programmed by Marie-Edith Bissey.
} 
one's own relative performance $\left(M_{i}\right)$, money coming from the Hault\&Laury (2002) lottery $\left(L_{i}\right)$ and the payment of $3 €$ for the questionnaire $\left(Q_{i}\right)$. Thus:

$P_{i}=E_{i}+M_{i}+L_{i}+Q_{i}$

The amount of tokens earned during the treatment depends both on the selected contract and the class $\mathrm{k} \in\{\mathrm{H}, \mathrm{M}, \mathrm{L}\}$ player $i$ belongs to. Thus:

$E_{i k}=I_{i k}-T_{i k}+E F_{i}$

Where $I_{i k}$ and $T_{i k}$ are respectively the income of and the tax paid by player $i$ depending on his class k. $E F_{i}$ is the expected amount of tokens received by the fund after unlucky people are refunded. This amount does not depend on the class.

Given that the income of a rich subject $\left(I_{H}\right)$ is 300 , while a middle-class participant is endowed with 200 tokens $\left(I_{M}\right)$ and a poor with $100\left(I_{L}\right)$, the relative earnings $\left(E_{H}, E_{M}, E_{L}\right)$ are computed as follows:

Under the Proportional contract (Neutral Welfare State), where the tax rate is $30 \%$ for everyone, the tax paid by rich, middle-class and poor people is respectively:

$T_{H A}=0.3 * 300=90$

$T_{M A}=0.3 * 200=60$

$T_{L A}=0.3 * 100=30$

Consequently, since in each session 21 subjects ( 7 per class) participate, the fund $\left(F_{A}\right)$ is equal to:

$F_{A}=7 * 90+7 * 60+7 * 30=1260$

The sum equally redistributed among players is net of the amount of tokens used to refund unlucky people. The expected amount of this refunding sum $(E R)$ is:

$E R=7 * 0.4 * 80+7 * 0.5 * 80+7 * 0.6 * 80=840$

This means that the expected amount of tokens each subject receives from the fund $\left(E F_{A}\right)$ is:

$E F_{A}=420 / 21=20$

Consequently:

$E_{H A}=300-90+20=230$

$E_{M A}=200-60+20=160$

$E_{L A}=100-30+20=90$ 
Under the Actuarially-fair contract (Individualistic Welfare State), where the tax consists of two components - a $10 \%$ tax rate plus a part proportional to risk - the tax paid by rich, middle-class and poor people is respectively:

$T_{H B}=0.1 * 300+0.4 * 80=62$

$T_{M B}=0.1 * 200+0.5 * 80=60$

$T_{L B}=0.1 * 100+0.6 * 80=58$

The fund $\left(F_{B}\right)$ is equal to:

$F_{B}=7 * 62+7 * 60+7 * 58=1260$

This means that the expected amount of tokens each subject receives from the fund $\left(E F_{B}\right)$ is again 20

Consequently:

$E_{H B}=300-62+20=258$

$E_{M B}=200-60+20=160$

$E_{L B}=100-58+20=62$

Under the progressive contract (Prioritarian Welfare State), where tax rate is 35\%, 30\% and 15\% for reach, middle-class and poor respectively, the tax paid is:

$T_{H C}=0.35 * 300=105$

$T_{M C}=0.3 * 200=60$

$T_{L C}=0.15 * 100=15$

The fund $\left(F_{C}\right)$ is equal to:

$F_{C}=7 * 105+7 * 60+7 * 15=1260$

This means that the expected amount of tokens each subject receives from the fund $\left(E F_{C}\right)$ is again 20

Consequently:

$E_{H C}=300-105+20=215$

$E_{M C}=200-60+20=160$

$E_{L C}=100-15+20=105$ 
Table 1 compares the redistributive power of each contract. What it turns out is that the 'Individualistic' Welfare State makes poor even poorer in relative terms, while the 'Prioritarian' State strongly reduces relative differences.

\section{Theoretical predictions}

Starting from a simply economic consideration, we expect that self-interested subjects will choose the taxation scheme that maximizes their expected payoff. According to the payoff analyses presented in the previous section, this means that, in the VOI scenario, people who expect to be rich will choose the actuarially fair Individualistic contract, while expected poor people will choose the progressive Prioritarian contract. The same principle holds in the NO_VOI scenario: the rich will choose the Individualistic State while the poor will choose the Progressive one. Concerning the middle class, there is no economic reason to prefer any of the Welfare States. In fact, their expected payoff is the same, no matter the contract. Obviously, we expect that people change their choices in the NO_VOI condition with respect to the VOI condition if their prediction on their relative performance is in contrast with the actual result.

To sum up:

Hypothesis 1 (H1): The expected/actual rich will choose the Individualistic State

Hypothesis 2 (H2): The expected/actual poor will choose the Progressive State

Hypothesis 3 (H3): The expected/actual middle class will be indifferent. Consequently, they will randomly choose one of the contracts.

Hypothesis 4 (H4): Participants will change their choices in the NO_VOI condition with respect to the VOI condition if their prediction on their relative performance is wrong.

\section{Data analysis and results}

\subsection{The sample}

Overall, 147 undergraduate students participated in the experiment - 63 from the University of Turin, 42 from the University of Milano-Bicocca and 42 from the University of Eastern Piedmont. Since subjects' choices are not significantly different across locations, we perform our analysis on the pooled sample. ${ }^{13}$

\footnotetext{
${ }^{13}$ Chi-squared tests run on contingency tables where choices and locations are coupled (both in the VOI and in the NO_VOI scenario) do not reject the null hypothesis of independence $(p>0.43)$
} 
At the end of each experimental session we collect, through a questionnaire, data concerning participants' socio-demographic characteristics, attitudinal views about society and risk tolerance. This allows testing to what extent these issues play a role in determining people's choices.

Concerning socio-demographic characteristics, we collect data on age, gender, religious affiliation, volunteering activities, job, political orientation and school career. In our sample, $42 \%$ were men. On average, they were 24 -year old and $28 \%$ were workers. Sixty-six percent were believers $(60 \%$ Catholics) and 35\% were volunteers. Thirty-four percent were left-wing. If we look at their school career, $17 \%$ only scored less than 70 as high-school final mark; while 80 is both the mean and the median value. $^{14}$

A second set of questions is focused on the reasons why some people succeed in life while some others fail. More specifically, we ask subjects: 'Below are listed several reasons why some people get ahead and succeed in life and others do not. Using a 1-5 scale, where '1' means "Of no significance" and '5' means "extremely important", please tell me how important it is as a reason for a person's success: a) willingness to take risk; b) money inherited from families; c) hard work and initiative; d) ability or talent a person is born with; e) good looks; f) connections; g) being a member of a particular race or ethnic group; $h$ ) getting the suitable education; i) gender'. For each item, subjects have to select a value from 1 to 5 where 1 means 'Of no significance' and 5 means 'extremely relevant'. Since it is possible to identify two classes of factors - intrinsic and contextual - we construct two indices. The SKILL_INDEX is computed as the mean of the values subjects select for a), c), d) and h) items, while the PERSONAL_INDEX is the mean of subjects' choices in the remaining items. Overall, people seem to consider intrinsic factors more relevant than the contextual ones. In fact, the average value of the SKILL_INDEX is significantly higher than the average value of the PERSONAL_INDEX (4.07 vs 3.05, Wilcoxon test, $\mathrm{p}=0.000$ ).

In the questionnaire we detect participants' attitude towards the Welfare State. Subjects are asked: 'Which of the following sentences is more in line with your way of thinking?': A) We should live in a society where the size of the Government is large even if taxes are high; B) We should live in a society where the tax burden is low but everyone should take care of herself.'

Around $60 \%$ of our experimental subjects choose option A.

Two further questions deal with participants' perception of their status, both in the lab and in real life. First of all, before performing the task, we ask them to predict the category they will belong to. Then, we ask them their expectation for the future through the following question: 'In Italy, people like you and your family are likely to improve their standard of living'. Subjects have to select a value from 1 to 5 where 1 means 'I do not agree at all' and 5 means 'I completely agree'.

\footnotetext{
${ }^{14}$ In Italy, the high-school final mark ranges from 60 to 100.
} 
About $33 \%$ of the participants think that they will be in the rich group, while $56 \%$ think they will belong to the middle class while only $11 \%$ believe that they will end in the poor category. Only $39 \%$ of them provide a correct prevision. Concerning people's expectations for future, they turn out to be not extremely optimistic: half of them do not agree on the fact that there will be the opportunity of improving their standard of living, while only less than $2 \%$ completely agree.

Finally, subjects' attitude towards risk is measured through a set of questions where we ask: 'What is your attitude towards risk for each of the specific contexts? a) Car driving; b) Money matters ; c) Leisure and sport activities; d) Career; e) Health'. For each item, subjects had to tick a value from 0 to 10 where 0 means 'Completely risk averse' and 10 means 'Completely willing to accept risk'. We then compute two indices: the FINANCIAL_RISK $i$ index is computed as the mean of the values subject $i$ selects for b) and d) items, while the PHYSICAL_RISK $K_{i}$ index is the mean of subject $i$ 's tolerance in the remaining items. In our sample, people are more willing to take financial risks than physical ones (5.52 vs 4.72; Wilcoxon test, $\mathrm{p}=0.000)$.

In the next session we will detect whether and to what extent these characteristics influence subjects' decision-making process.

\subsection{Results}

Result 1. Subjects' choices are driven by self-interested considerations both under the veil of ignorance and when the veil drops.

From Table 2, it emerges that both under the VOI and the NO_VOI scenario, the most favoured contract is the actuarially fair one - the Individualistic Welfare State. The second favoured State is the Prioritarian one based on a progressive tax system. However, even if choices under the two scenarios seem to be in line, when we study subjects' coherence in the two situations, it turns out that only 78 subjects out of 147 confirm their choice once the veil is lifted. Thus, 69 subjects revise their choice.

\section{[TABLE 2 HERE]}

How can we explain this evidence? The key point is to try and understand what factors drive people's choices in both scenarios and lead most of them to switch when the veil drops. Since in each scenario people can choose among three possible options that can be ordered in terms of redistributive power, we select the ordered-probit model as the most suitable econometric tool. ${ }^{15}$ The two specifications are:

\footnotetext{
${ }^{15}$ We performed a further analysis running a multinomial logit. The results do not change.
} 
CHOICE_VOI ${ }_{i}=\alpha+\beta_{1}$ GUESS_FIRST $T_{i}+\beta_{2} G U E S S_{-} L A S T_{i}+\beta_{3}$ WELFARE_STATE ${ }_{i}+$ $+\beta_{4} S T A T U S_{-} I M P R O V E M E N T_{i}+\sum_{r} \eta_{r} D E M O G_{i}+\sum_{s} \gamma_{s} R I S K_{-} I N D I C E S_{i}+$ $+\sum_{z} \omega_{z} S U C C E S S \_I N D I C E S_{i}+\varepsilon_{i}$

Where:

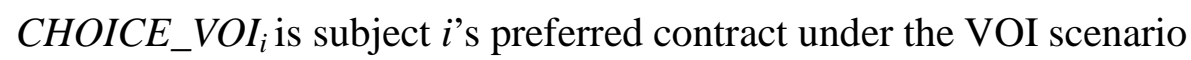

GUESS_FIRST $T_{i}$ is a dummy variable equal to 1 if subject $i$ thinks he will be in the first category (rich)

GUESS_LAST $T_{i}$ is a dummy variable equal to 1 if subject $i$ thinks he will be in the third category (poor)

$W E L F A R E_{i}$ is a dummy variable equal to 1 if subject $i$ chooses option $\mathrm{A}$ in the question aimed at detecting her attitude towards the Welfare State, 0 otherwise

STATUS_IMPROVEMENT $i$ is a variable reporting subject $i$ 's answer to the question detecting her level of agreement concerning the opportunity to improve her standard of living in the future

$D E M O G_{i}$ is a series of demographic controls including age, gender, religious belief, volunteering activities, job and political orientation ${ }^{16}$

$R I S K_{-} I N D I C E S_{i}$ are the two measures of risk: FINANCIAL_RISK $K_{i}$ and PHYSICAL_RISK

SUCCESS_INDICES $S_{i}$ are the two indices reporting subject i's perception of the role played by different factors in determining people's success: SKILL_INDEX $X_{i}$ and PERSONAL_INDEX $\mathrm{i}_{\mathrm{i}}$

and

CHOICE_NO_VOI ${ }_{i}=\alpha+\beta_{1}$ FIRST $_{i}+\beta_{2} L A S T_{i}+\beta_{3}$ WELFARE_STATE $E_{i}+$ $+\beta_{4} S T A T U S \_I M P R O V E M E N T_{i}+\Sigma_{r} \eta_{r}$ DEMOG $_{i}+\sum_{z} \omega_{z}$ SUCCESS_INDICES $_{i}+\boldsymbol{\varepsilon}_{i}$

Where:

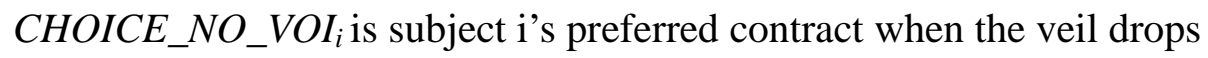

$\operatorname{FIRST}_{i}$ is a dummy variable equal to 1 if subject $i$ belongs to the first category (rich)

$L A S T_{i}$ is a dummy variable equal to 1 if subject $i$ belongs to the third category (poor)

${ }^{16}$ We dropped the high-school final mark because of its significant correlation with the expected category. 
What turns out is that, in both scenarios, belonging to a certain - hypothesized or real - category strongly matters. In other words, the rich (expected or actual) are more likely to choose the Individualistic State while poor people are more likely to vote for the Prioritarian one. More specifically, people who think they will be in the rich category are $28 \%$ more likely to choose the actuarially-fair contract and $22 \%$ less likely to vote for the progressive one. When the veil drops, this effect is even stronger. In fact, rich people are 50\% more likely to vote for the actuarially-fair contract and $42 \%$ less likely to opt for the progressive one. At the same time, poor people are $23 \%$ more likely to vote for the progressive contract and $21 \%$ less likely to choose the actuarially-fair option. Moreover, the actuarially-fair contract is the least favoured contract among the poor while the progressive contract is the last choice for most of the rich. Notice that this is perfectly in line with $\mathrm{H} 1$ and $\mathrm{H} 2$ : the principle of self-interest maximization holds since category 1 and category 3 get the highest pay-offs under the actuarially-fair contract and the progressive contract respectively. Tables 3 and 4 report the results of the econometric analysis while Tables 5 to 8 focus on the specific relation between the hypothesized/real category and choices.

\section{[TABLES 3 to 8 HERE]}

This result is strengthened if we analyze in detail what makes people switch to a different contract as soon as the veil drops. We concentrate attention on the change in choices when the veil is lifted and subjects become aware of their category. We focus on the actuarially-fair contract and on the progressive one. In fact, these two contracts share the feature of being those that maximize the payoff for the "rich" and the "poor", respectively.

Under the VOI condition, 66 subjects are in favour of the actuarially-fair contract. Out of 66 subjects, only 3 - those participants who expect to belong to the third category - vote against their self-interest._What do those 66 subjects do when the veil is lifted (see Table 9)? It turns out that 35 choose again the actuarially-fair contract ( 22 belong to the rich and 10 to the middle class); instead 24 subjects - 16 poor, and 7 belonging to the middle class - decide to vote for the progressive contract.

In the VOI scenario, 41 subjects are in favour of the progressive contract. Only 4 out of 41 - those who expect to belong to the first category - vote against their self-interest. What do they do when the veil is lifted (see Table 10)? It turns out that 24 choose again the progressive contract (11 are poor, and 12 belong to the middle class); instead, 11 subjects decide to vote for the actuarially-fair contract, 9 of them being rich. 


\section{[TABLES 9 AND 10 HERE]}

We run a probit regression whose specification is:

$\mathrm{SWITCH}_{i}=\alpha+\beta_{1}$ GUESS $_{i}+\beta_{2}$ WELFARE_STATE $_{i}+\beta_{4}$ STATUS_IMPROVEMENT $_{i}+\sum_{r} \eta_{r}$ DEMOG $_{i}$ $+\sum_{s} \gamma_{s} R I S K \_I N D I C E S_{i}+\sum_{z} \omega_{z} S U C C E S S \_I N D I C E S_{i}+\varepsilon_{i}$

where:

$\mathrm{SWITCH}_{i}$ is a dummy variable equal to 1 if subject $i$ selects a different contract when the veil drops, 0 otherwise

$G U E S S_{i}$ is a dummy variable equal to 1 if subject $i$ correctly predict the category she will belong to, 0 otherwise

\section{[TABLE 11 HERE]}

From R3, it turns out that the only reason to change one's mind when the veil drops is that the prediction of one's position in the society was wrong. This is in line with H4.

To sum up, those subjects who under the VOI condition prefer the Individualistic income distribution think either they are high-ability subjects or they belong to the middle-class (which is favoured by no contract), while the Prioritarian is preferred by those who think they are poor (or, again, belong to the middle-class). Without the veil of ignorance, the same scenario emerges, as subjects appear to lean towards self-interest: the rich prefer the Individualistic distribution, and the poor are in favour of the Prioritarian contract.

Another point that emerges from the econometric analysis is that, when the veil drops, belonging to a specific category seems to be the only factor that plays a role. However, under the veil of ignorance other factors matters. In particular, men are more likely to choose the actuarially-fair contract while students who have a job and people who declare to prefer living in a society where the size of the Government is large even if taxes are high, are more likely to opt for the progressive contract. This is a challenging result that deserves further inquiry in future research.

Result 2. Under the VOI condition most of the expected middle class participants opt for the actuarially fair contract, while under the NO_VOI condition the preferred contract of the actual middle class is the progressive one. 
Given the relevance of self-interest shown by the results so far analysed, we turn to a deeper study of the behaviour of the middle-class, as these subjects cannot be motivated by self-interest in the choice of the Welfare State contract.

Let us start from the hypothetical middle-class under the VOI - those 83 participants who believe that they will belong to the middle class once the veil drops. From Table 5 we know that the actuarially-fair contract is the first preferred (35 people chose it), while the progressive contract comes second (chosen by 29 subjects). Shifting to the NO_VOI condition (Table 6), we see that the progressive contract is the one favoured by the actual middle class ( 20 out of 49 choose it). A reason for these inconsistent choices is certainly the fact that the two groups of the expected middle class and the actual middle class do not match. In fact, only 30 subjects make a correct prediction of belonging to the middle class. Twenty-three of them are perfectly consistent in their choices over the two scenarios, and only 8 of them prefer the actuarially fair contract (see Table 12). Moreover, among the 14 subjects who thought to be rich - and in fact are middle-class when the veil is lifted only 3 prefer the actuarially-fair contract. Even if 8 of them were in favour of the actuarially-fair contract under VOI, only 2 when the veil is lifted confirm their vote. The disappointment about their actual ability and earnings ranking may play a role in explaining this finding. Finally, among the 5 people who thought to be poor - and in fact are middle-class when the veil is lifted - 4 were in favour of the progressive contract under VOI and 3 confirm their choice when the veil is lifted.

\section{[TABLE 12 HERE]}

Again, we run an ordered probit regression in order to better understand middle-class participants' choices. The specification is:

CHOICE_NO_VOI ${ }_{i}=\alpha+\beta_{1} G U E S S \_F I R S T_{i}+\beta_{2} G U E S S \_L A S T_{i}+\beta_{3} W E L F A R E \_S T A T E_{i}+$ $+\beta_{4}$ STATUS_IMPROVEMENT ${ }_{i}+\beta_{5}$ FIRST_PROGRESSIVE $E_{i}+\beta_{6}$ FIRST_ACTFAIR $_{i}+$ $+\sum_{r} \eta_{r} D E M O G_{i}+\Sigma_{z} \omega_{z} S U C C E S S_{-} I N D I C E S_{i}+\varepsilon_{i}$

\section{[TABLE 13 HERE]}

What turns out is that people who thought to be in the first category and those who opted for the progressive contract under the VOI are more likely to choose the Prioritarian Welfare State. At the 
same time, those who are in favour of living in a society where the size of the Government is large even if taxes are high, are more likely to opt for the proportional contract.

What happens to the 53 subjects who, under the VOI condition, wrongly predict to be in the middle class? Twenty-five are actually rich and 19 of them choose the actuarially-fair contract (12 of them selected a different contract under VOI), while 28 are poor and 19 of them choose the progressive contract (11 of them chose a different contract under VOI). This implies that, as far as they realize they are in a class that is favoured by a specific contract, they change their mind and choose it (see Table 14).

\section{[TABLE 14 HERE]}

How can we interpret this evidence? In our design the voting on the Welfare State by the middle class is not meant to set up an "impartial" social choice, but just to exploit this feature of the experimental model with the aim to detect a "pure" taste for solidarity. We think that the protocol so far described is able to endogenously reveal a "pure" attitude to other-regarding behaviour. When under VOI the subject makes his decision about the tax rate, he is free to declare he expects to fall in the category that is indifferent towards possible redistributive consequences of the chosen contract, or in any one of the other two categories. If he votes in favour of the Prioritarian contract and then confirms this preference even if he happens to be a "middle class" subject, his "impartial" standpoint is a guarantee of his "pure" taste for solidarity.

Under the VOI condition, most of the middle-class subjects prefer either the Individualistic Welfare State or the Prioritarian one. The former are probably driven by the belief that people who are poor are responsible for their situation and, consequently, the rich should not be coerced to help them. The latter are probably more prone to think that the society is plagued by inequality of opportunity and that more lucky people should bear part of the risk associated to poor people.

How should we evaluate the finding that - without the VOI - the subjects belonging to the middleclass seem to be more inclined to choose the Prioritarian contract? This group of middle income people is composed not only of subjects who take account of the fact of being less skilled (and thus less rich) than expected and switch to this contract when the VOI is dropped, but also of subjects who confirm their choice in favor of the redistributive Welfare State. This latter sub-group keeps preferring the Prioritarian contract against their self-interest. This preference, though these subjects 
are in a position of indifference about what tax \& transfers mechanism should be implemented, naturally points to social preferences. ${ }^{17}$.

All in all, the choice of the middle class is the result of two different dynamics: the coherence of people who correctly predicted their affiliation to the middle-class and confirm their choice, and the disappointment of people who thought to be the best performers and decide to become egalitarian as soon as they realize they are not so good. Finally, the belief of belonging to the middle class has no effect on choices in the NO_VOI scenario. As soon as subjects realize that their actual class is favored by a contract, they opt for it. In other words, self-interest is definitely stronger than any other motivation.

\section{Discussion and conclusions}

Our setup, though utterly parsimonious, was neatly arranged to elicit the preference for a Welfare State under the veil of ignorance. Two contracts are symmetrically positioned to favour the pursuit of self-interest by each of two classes, respectively, whereas no contract is to be preferred by the third class. The main tendencies which stand out from our experiment are as follows.

1) The "actuarially fair" contract is preferred by those who are (or think they are) at the top of the ability - and thus earnings - ranking, while the Progressive contract is preferred by those who are (or think they are) at the bottom of the ability - and thus earnings - ranking. Moreover, most of the people who switch to a different contract when the veil of ignorance drops, actually choose the system of taxation that guarantees them the highest earnings.

2) The middle-class behaves differently with or without the VOI. In particular, under VOI these subjects do not think that being relatively more exposed to risk is a reason for waiving merit as a principle of justice; instead, without the VOI, most of them change their mind, as their voting turns out to be in favour of redistribution.

We opened the paper with the question whether voters are favourably disposed towards the move in the direction of "individual responsibility" that most Welfare States of advanced countries are implementing. From our experiment, the answer is no for several reasons. First of all, if we look at the percentage of people who prefer a specific contract, both under the VOI condition and under the NO_VOI scenario, it emerges that subjects are almost split between the Individualistic and the Prioritarian Welfare State. This implies that there is no strong and defined preference for an actuarially-fair regime. Moreover, we show that preferences are driven by expectations - under the VOI - and by the effective position in the society - in the NO_VOI scenario. As we said before, this

\footnotetext{
17 A noticeable reference is to Fehr and Schmidt (1999), who found experimental confirmation of other-regarding behaviour as represented in a design where inequality aversion is lower for other people's income than for own income.
} 
is clear when we analyse the behaviour of our "rich" and our "poor". This may imply that when citizens ask for more "individual responsibility" in the welfare regime, they are not driven by idealistic principles of justice, but simply by their self- interest. In other words, they believe that under an Individualistic Welfare State they will be good enough to improve their position within the society. Finally, let us focus on our "middle class". As we explained in details in the previous sections, our experimental "middle class" is, by construction, indifferent among the three Welfare States we propose. Even though we are aware that it is not a perfect representation of a real-life middle-class, we think that the characteristic of being advantaged by no specific contract may help us to disentangle ideological from self-interested motivations. What emerges from our results is that this "middle-class" does not show any particular inclination towards the "actuarially fair" contract. In fact, if under the veil of ignorance the actuarially fair contract is slightly preferred to the progressive one, when the veil is lifted the progressive contract becomes the preferred one. Obviously, this is due to the fact that the two populations are not identical. In particular, among people that now belong to the "middle class", we could observe that subjects who predicted they would belong to the "rich" under the VOI and chose the actuarially fair contract, as the veil is removed and they discover they belong to the "middle class", shift to the progressive contract. This choice does not influence their income. We can explain this result in terms of disappointment. In other words, as a subject who thinks she is in the upper class of a society discovers that this is not the case, the disappointment leads her to choose the "solidaristic" distribution of resources, even if it provides no direct monetary advantages. This observation reinforces our findings that people choose a system, and in particular an actuarially-fair system, if they predict and observe a material gain from that.

Of course, our experimental results can just represent a clue to how the general opinion is evolving about the way in which institutions of social protection are to be devised. Indeed, this caution remark is also driven by the close turn-out summarised as Result 1 . Since our subjects, after the veil is lifted, almost split their preferences between the "actuarially fair" and the "progressive" fiscal system, we are induced to think that overall voting on redistributive Welfare institutions very much depends upon the composition of the population. Indeed, many studies inquiring into income inequality in advanced countries show that the kernel of income distribution is evolving towards bimodality (for a recent overview, see Gornik and Jantti, 2013).

Since our results suggest that majority voting in advanced countries responds to self-interested motivations, this modification in the constituency is bound to further polarize preferences for the Welfare State. The policy implication may be that public policies should focus on individual conditions of life. Welfare institutions should not be solely confined to promoting a lower 
disposable income inequality, and to the reshuffling of earnings across deciles enacted by the taxand-transfers system through "mutual risk insurance". A lower distance among individual levels of well-being would also be promoted by the exploitation of several linkages between income inequality and inequality of opportunity as stressed in the Introduction. The objective of "individual responsibility" could be pursued by public programmes fostering human capital, devoted to raise individual ability and lower risk exposure. To the extent that a less unequal distribution of opportunities would enable individuals to improve their income prospects, market income distribution could become more "meritocratic" and social mobility be boosted. 


\section{References}

Acciari P. and S. Mocetti (2013), "Una mappa della disuguaglianza del reddito in Italia", Questioni di Economia e Finanza, Banca d'Italia.

Alesina A. and P. Giuliano (2009) "Preferences for Redistribution", in A. Bisin and J. Benhabib eds., Handbook of Social Economics, Amsterdam, North Holland.

Alesina A., E. Glaser and B. Sacerdote (2001) "Why doesn't the United states have a Europeanstyle welfare state?", Brookings Papers on Economic Activity, 2: 187-277.

Alesina A., G.Cozzi and N.Mantovan (2012) "The Evolution of Ideology, Fairness and Redistribution," Economic Journal, 122(565): 1244-1261.

Dworkin, R. (2000) Sovereign Virtue, Cambridge (Mass.), Harvard University Press

Fehr, E., and K. M. Schmidt (1999) "A Theory of Fairness, Competition, and Cooperation" Quarterly Journal of Economics, 114: 817-868.

Fischbacher, U. (2007) "z-Tree: Zurich toolbox for ready-made economic experiments," Experimental Economics, 10: 171-178.

Fleurbaey M. (2008) Fairness, Responsibility, and Welfare, Oxford, Oxford University Press.

Gornick J.C. and M. Jantti (2013) Income Inequality. Economic Disparities and the Middle Class in Affluent Countries, Stanford (Cal.), Stanford University Press.

Hassler J., J.V. Rodriguez Mora, K.Storesletten, and F.Zilibotti (2003) "The Survival of the Welfare State", American Economic Review, 93: 87-112.

Holt, C.A. and S.K. Laury (2002) "Risk Aversion and Incentive Effects", American Economic Review, 92: 1644-1655.

Konow, J. (2000) "Fair shares: accountability and cognitive dissonance in allocation decisions," American Economic Review, 90: 1072-1091.

Konow, J. (2001) "Fair and square: the four sides of distributive justice," Journal of Economic Behavior \& Organization, 46(2): 137-164.

Krawczyk, M. (2010) "A glimpse through the veil of ignorance: Equality of opportunity and support for redistribution," Journal of Public Economics, 94: 131-141.

Marical F., M. Mira D'Ercole, M. Vaalavuo, and G. Verbist (2006) "Publicly provided services and the distribution of resources", OECD Social, Employment and Migration Working Paper N. 4549.

OECD (2008) Growing Inequal?, Income distribution and poverty in OECD Countries, Paris.

OECD (2011) How's Life? Measuring Well-Being, Paris.

Paladini, R. (2011), "Irpef, tre aliquote e tre montagne da superare", mimeo.

Rawls J. (1971) A Theory of Justice, Oxford, Clarendon Press

Rawls J. (1991) A Theory of Justice, Cambridge (Mass.) Belknap Press of Harvard University Press,

Roemer J.E. et al. (2003) "To what extent do fiscal regimes equalize opportunities for income acquisition among citizens?", Journal of Public Economics, 87: 539-565

Roemer, J.E. (2000). Equality of Opportunity, Cambridge (Mass.), Harvard University Press.

Sen A.K. (1993) "Markets and Freedoms. Achievements and limitations of the market mechanism in promoting individual freedoms", Oxford Economic Papers, 45: 519-541. 
Sen A.K. (2009) The Idea of Justice, Allen Lane \& Harvard University Press..

Sinn, H.-W. (1995). "A theory of the welfare state," Scandinavian Journal of Economics, 97(4): 495-526.

Thurow, L. (1971). "The income distribution as a pure public good," Quarterly Journal of Economics, 85(2): 327-336.

Wilkinson R.G. and K. Pritchett (2009) The Spirit Level: Why More Equal Societies Almost Always Do Better, New York, Bloomsbury Press. 
TABLES AND FIGURES

Figure 1. Experimental Design

Determine the missing square choosing among options A, B, C, D and E
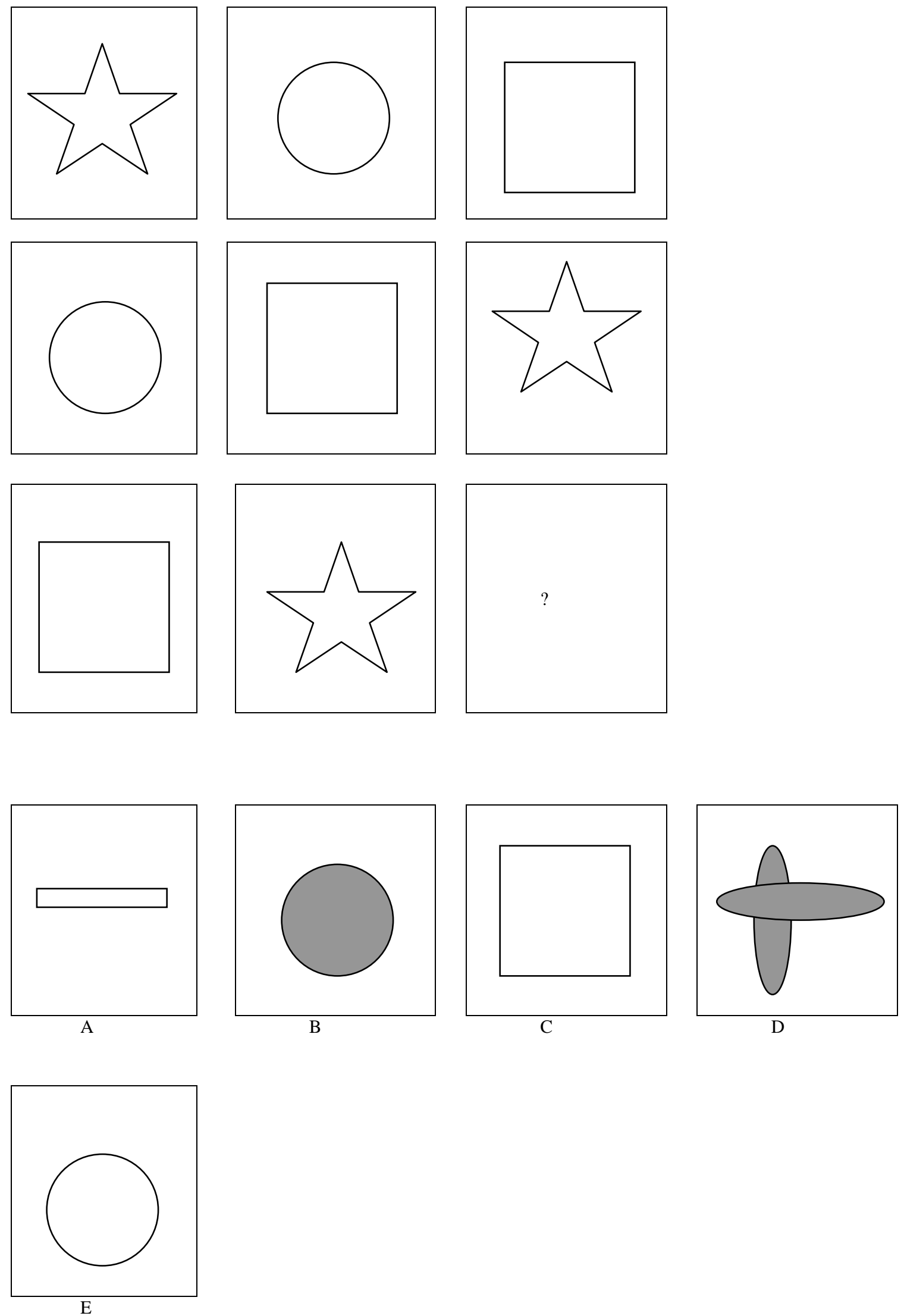
Figure 2. Experimental Design

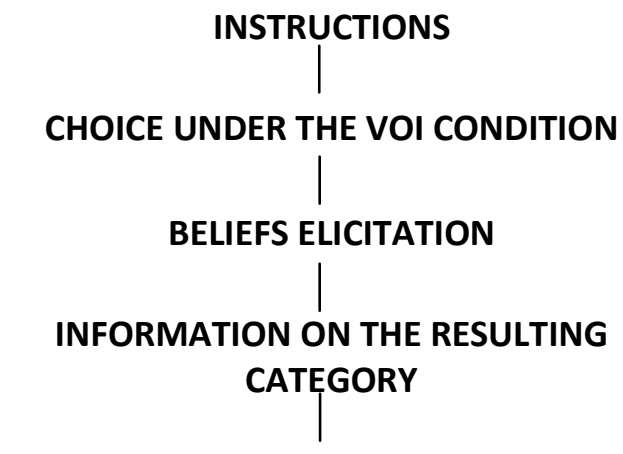

CHOICE UNDER THE NO_VOI CONDITION

QUESTIONNAIRE

PAYMENT

Table 1. The three Welfare State contracts and expected income variance

\begin{tabular}{|c|cc|cc|cc|cc|}
\hline & \multicolumn{1}{|c|}{ Initial situation } & \multicolumn{2}{|c|}{ Neutral } & \multicolumn{2}{|c|}{ Individualistic } & Prioritarian \\
\hline Class & Income & $\begin{array}{c}\text { Relative } \\
\text { Income (RI) }\end{array}$ & $\begin{array}{c}\text { Expected } \\
\text { Income (EA) }\end{array}$ & $\begin{array}{c}\text { Relative } \\
\text { Expected } \\
\text { Income } \\
\text { (REA) }\end{array}$ & $\begin{array}{c}\text { Expected } \\
\text { Income } \\
\text { (EB) }\end{array}$ & $\begin{array}{c}\text { Relative } \\
\text { Expected } \\
\text { Income } \\
\text { (REB) }\end{array}$ & $\begin{array}{c}\text { Relative } \\
\text { Expected } \\
\text { Income (EC) }\end{array}$ & $\begin{array}{c}\text { Expome } \\
\text { InEC) }\end{array}$ \\
\hline Rich & 300 & 3 & 230 & 2.5 & 258 & 4.2 & 215 & 2 \\
\hline $\begin{array}{c}\text { Middle } \\
\text { Class }\end{array}$ & 200 & 2 & 160 & 1.8 & 160 & 2.6 & 160 & 1.5 \\
\hline Poor & 100 & 1 & 90 & 1 & 62 & 1 & 105 & 1 \\
\hline
\end{tabular}

Table 2

\begin{tabular}{|c|c|c|c|c|}
\hline & & \multicolumn{3}{|c|}{ NO_VOI condition } \\
\hline \multirow{3}{*}{ VOI condition } & Progressive & Proportional & $\begin{array}{c}\text { Actuarially } \\
\text { fair }\end{array}$ \\
\hline & Progressive & 24 & 6 & 11 \\
\cline { 2 - 5 } & Proportional & 8 & 19 & 13 \\
\cline { 2 - 5 } & $\begin{array}{c}\text { Actuarially } \\
\text { fair }\end{array}$ & 24 & 7 & 35 \\
\hline
\end{tabular}


Table 3. Ordered Probit Regression (R1) - Marginal effects

Dependent variable: CHOICE_VOI

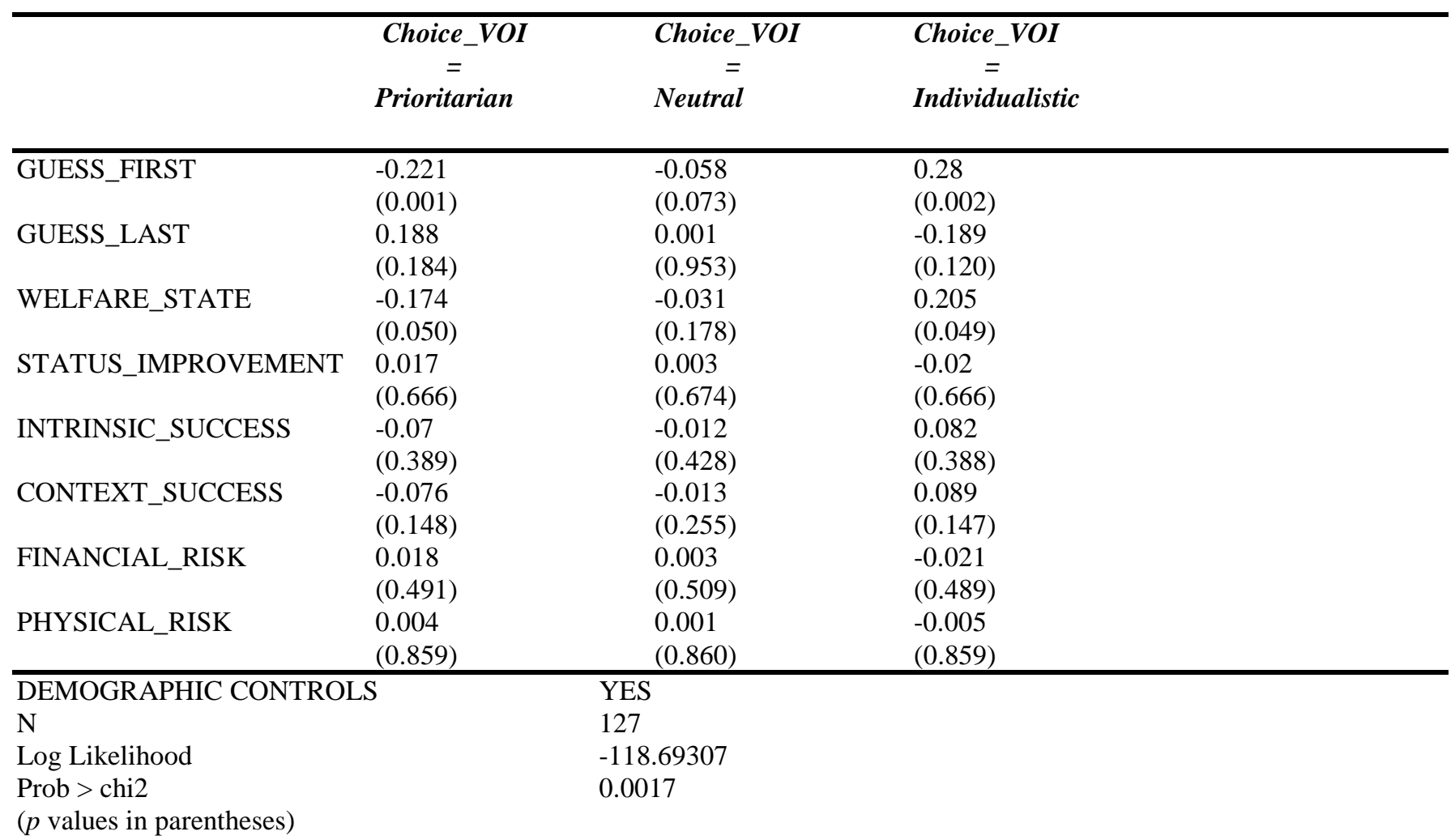

Table 4. Ordered Probit Regression (R2) - Marginal effects

Dependent variable: CHOICE_NO_VOI

\begin{tabular}{|c|c|c|c|}
\hline & $\begin{array}{l}\text { Choice_NO_VOI } \\
= \\
\text { Prioritarian }\end{array}$ & $\begin{array}{c}\text { Choice_NO_VOI } \\
= \\
\text { Neutral }\end{array}$ & $\begin{array}{c}\text { Choice_NO_VOI } \\
= \\
\text { Individualistic }\end{array}$ \\
\hline$\overline{\text { FIRST }}$ & $\begin{array}{l}-0.422 \\
(0.000)\end{array}$ & $\begin{array}{l}-0.076 \\
(0.127)\end{array}$ & $\begin{array}{l}0.498 \\
(0.000)\end{array}$ \\
\hline LAST & $\begin{array}{l}0.227 \\
(0.025)\end{array}$ & $\begin{array}{l}-0.018 \\
(0.492)\end{array}$ & $\begin{array}{l}-0.209 \\
(0.015)\end{array}$ \\
\hline WELFARE_STATE & $\begin{array}{l}-0.114 \\
(0.242)\end{array}$ & $\begin{array}{l}0.0005 \\
(0.962)\end{array}$ & $\begin{array}{l}0.114 \\
(0.242)\end{array}$ \\
\hline STATUS_IMPROVEMENT & $\begin{array}{l}0.058 \\
(0.198)\end{array}$ & $\begin{array}{l}-0.0003 \\
(0.962)\end{array}$ & $\begin{array}{l}-0.058 \\
(0.196)\end{array}$ \\
\hline INTRINSIC_SUCCESS & $\begin{array}{l}-0.095 \\
(0.292)\end{array}$ & $\begin{array}{l}0.0004 \\
(0.962)\end{array}$ & $\begin{array}{l}0.095 \\
(0.291)\end{array}$ \\
\hline CONTEXT_SUCCESS & $\begin{array}{l}-0.012 \\
(0.834)\end{array}$ & $\begin{array}{l}0.0001 \\
(0.963)\end{array}$ & $\begin{array}{l}0.012 \\
(0.834)\end{array}$ \\
\hline \multicolumn{2}{|l|}{ DEMOGRAPHIC CONTROLS } & \multicolumn{2}{|l|}{ YES } \\
\hline \multicolumn{2}{|l|}{$\mathrm{N}$} & \multicolumn{2}{|l|}{128} \\
\hline \multicolumn{2}{|l|}{ Log Likelihood } & \multicolumn{2}{|l|}{-104.32398} \\
\hline Prob $>$ chi 2 & ( $p$ values in parentheses) & \multicolumn{2}{|l|}{0.0000} \\
\hline
\end{tabular}


Table 5

\begin{tabular}{|c|c|c|c|c|}
\hline & & \multicolumn{3}{|c|}{ Favoured contract under the VOI condition } \\
\hline & & Progressive & Proportional & $\begin{array}{c}\text { Actuarially } \\
\text { fair }\end{array}$ \\
\hline \multirow{5}{*}{ Expected category } & Rich & $8.3 \%$ & $33.3 \%$ & $58.3 \%$ \\
& $(\mathbf{N}=\mathbf{4 8})$ & $(\mathrm{N}=4)$ & $(\mathrm{N}=16)$ & $(\mathrm{N}=28)$ \\
\cline { 2 - 5 } & Middle class & $34.9 \%$ & $22.9 \%$ & $42.2 \%$ \\
& $(\mathbf{N}=\mathbf{8 3})$ & $(\mathrm{N}=29)$ & $(\mathrm{N}=19)$ & $(\mathrm{N}=35)$ \\
\cline { 2 - 5 } & Poor & $50 \%$ & $31.2 \%$ & $18.8 \%$ \\
& $(\mathbf{N}=\mathbf{1 6})$ & $(\mathrm{N}=8)$ & $(\mathrm{N}=5)$ & $(\mathrm{N}=3)$ \\
\hline
\end{tabular}

Chi2 test: $p=0.002$

Fisher-exact test: $\mathbf{p}=\mathbf{0 . 0 0 1}$

Table 6

\begin{tabular}{|c|c|c|c|c|}
\hline & & \multicolumn{3}{|c|}{ Favoured contract under the NO_VOI } \\
condition
\end{tabular}

Chi2 test: $p=0.000$

Table 7

\begin{tabular}{|c|c|c|c|c|}
\hline & & \multicolumn{3}{|c|}{$\begin{array}{c}\text { Less favoured contract under the VOI } \\
\text { condition }\end{array}$} \\
\hline \multirow{5}{*}{ Expected category } & & Progressive & Proportional & $\begin{array}{c}\text { Actuarially } \\
\text { fair }\end{array}$ \\
\hline & Rich & $66.7 \%$ & $14.6 \%$ & $18.7 \%$ \\
& $(\mathbf{N}=\mathbf{4 8})$ & $(\mathrm{N}=32)$ & $(\mathrm{N}=7)$ & $(\mathrm{N}=9)$ \\
\cline { 2 - 5 } & Middle class & $33.7 \%$ & $34.9 \%$ & $31.3 \%$ \\
& $(\mathbf{N}=\mathbf{8 3})$ & $(\mathrm{N}=28)$ & $(\mathrm{N}=29)$ & $(\mathrm{N}=26)$ \\
\cline { 2 - 5 } & Poor & $37.5 \%$ & $12.5 \%$ & $50.0 \%$ \\
& $(\mathbf{N}=\mathbf{1 6})$ & $(\mathrm{N}=6)$ & $(\mathrm{N}=2)$ & $(\mathrm{N}=8)$ \\
\hline
\end{tabular}

Chi2 test: $p=0.001 \quad$ Fisher-exact test: $p=0.001 \quad$ Cramér's $V=0.2472$ 
Table 8

\begin{tabular}{|c|c|c|c|c|}
\hline & & \multicolumn{3}{|c|}{$\begin{array}{c}\text { Less favoured contract under the NO_VOI } \\
\text { condition }\end{array}$} \\
\hline & & Progressive & Proportional & $\begin{array}{l}\text { Actuarially } \\
\text { fair }\end{array}$ \\
\hline \multirow{3}{*}{ Category } & $\begin{array}{c}\text { Rich } \\
(\mathbf{N}=49)\end{array}$ & $\begin{array}{c}85.7 \% \\
(\mathrm{~N}=42)\end{array}$ & $\begin{array}{c}4.1 \% \\
(\mathrm{~N}=2)\end{array}$ & $\begin{array}{l}10.2 \% \\
(\mathrm{~N}=5)\end{array}$ \\
\hline & $\begin{array}{l}\text { Middle class } \\
(\mathrm{N}=49)\end{array}$ & $\begin{array}{c}26.5 \% \\
(\mathrm{~N}=13)\end{array}$ & $\begin{array}{c}30.6 \% \\
(\mathrm{~N}=15) \\
\end{array}$ & $\begin{array}{c}42.9 \% \\
(\mathrm{~N}=21)\end{array}$ \\
\hline & $\begin{array}{c}\text { Poor } \\
(N=49)\end{array}$ & $\begin{array}{c}22.5 \% \\
(\mathrm{~N}=11)\end{array}$ & $\begin{array}{l}12.2 \% \\
(\mathrm{~N}=6)\end{array}$ & $\begin{array}{c}65.3 \% \\
(\mathrm{~N}=32)\end{array}$ \\
\hline
\end{tabular}

Chi2 test: $p=0.000$ Cramér's $V=0.4442$

Table 9

\begin{tabular}{|c|c|c|c|c|}
\hline & & \multicolumn{3}{|c|}{$\begin{array}{r}\text { Favoured contract under the VOI } \\
\text { condition: Actuarially fair }\end{array}$} \\
\hline \multirow{4}{*}{ Category } & Progressive & Proportional & $\begin{array}{c}\text { Actuarially } \\
\text { fair }\end{array}$ \\
\hline & $\begin{array}{c}\text { Rich } \\
(\mathbf{N}=\mathbf{2 3})\end{array}$ & 1 & 0 & 22 \\
\cline { 2 - 5 } & $\begin{array}{c}\text { Middle class } \\
(\mathbf{N}=\mathbf{2 4})\end{array}$ & 7 & 7 & 10 \\
\cline { 2 - 5 } & $\begin{array}{c}\text { Poor } \\
(\mathbf{N}=\mathbf{1 9})\end{array}$ & 16 & 0 & 3 \\
\hline
\end{tabular}

Table 10

\begin{tabular}{|c|c|c|c|c|}
\hline & & \multicolumn{3}{|c|}{$\begin{array}{c}\text { Favoured contract under the VOI } \\
\text { condition: Progressive }\end{array}$} \\
\hline \multirow{4}{*}{ Category } & Progressive & Proportional & $\begin{array}{c}\text { Actuarially } \\
\text { fair }\end{array}$ \\
\hline & $\begin{array}{c}\text { Rich } \\
(\mathbf{N}=\mathbf{1 5})\end{array}$ & 1 & 5 & 9 \\
\cline { 2 - 5 } & $\begin{array}{c}\text { Middle class } \\
(\mathbf{N}=\mathbf{1 3})\end{array}$ & 12 & 1 & 0 \\
\cline { 2 - 5 } & $\begin{array}{c}\text { Poor } \\
(\mathbf{N}=\mathbf{1 3})\end{array}$ & 11 & 0 & 2 \\
\hline
\end{tabular}


Table 11. Probit Regression (R3) - Marginal effects

Dependent variable: SWITCH

$\begin{array}{lll}\text { GUESS } & -0.59 & \\ & (0.000) & \\ \text { WELFARE_STATE } & -0.046 & \\ & (0.706) & \\ \text { STATUS_IMPROVEMENT } & -0.037 & (0.517) \\ & -0.087 & \\ \text { INTRINSIC_SUCCESS } & (0.411) & \\ & -0.002 & \\ \text { CONTEXT_SUCCESS } & (0.974) & \\ & 0.031 & \\ \text { FINANCIAL_RISK } & (0.411) & \\ \text { PHYSICAL_RISK } & -0.053 & \text { YES } \\ & (0.132) & 127 \\ \text { DEMOGRAPHIC CONTROLS } & -62.923137 \\ \mathrm{~N} & & 0.0000 \\ \text { Log Likelihood } & \\ \text { Prob > chi2 } & \\ \text { ( } p \text { values in parentheses }) & \end{array}$

Table 12

\begin{tabular}{|c|c|c|c|c|}
\hline & & \multicolumn{3}{|c|}{$\begin{array}{c}\text { Middle Class people who correctly predict } \\
\text { their status under the VOI condition }\end{array}$} \\
\hline & & \multicolumn{3}{|c|}{ Contract under NO_VOI } \\
\hline & & Progressive & Proportional & $\begin{array}{c}\text { Actuarially } \\
\text { fair }\end{array}$ \\
\hline \multirow{4}{*}{ Contract under VOI } & Progressive & 8 & 0 & 0 \\
\cline { 2 - 5 } & Proportional & 0 & 7 & 0 \\
\cline { 2 - 5 } & $\begin{array}{c}\text { Actuarially } \\
\text { fair }\end{array}$ & 3 & 4 & 8 \\
\hline
\end{tabular}


Table 13. Ordered Probit Regression (R4) - Marginal effects

Dependent variable: CHOICE_NO_VOI (for the middle class only)

\begin{tabular}{|c|c|c|c|}
\hline & $\begin{array}{c}\text { Choice_NO_VOI } \\
= \\
\text { Prioritarian }\end{array}$ & $\begin{array}{c}\text { Choice_NO_VOI } \\
= \\
\text { Neutral }\end{array}$ & $\begin{array}{c}\text { Choice_NO_VOI } \\
= \\
\text { Individualistic }\end{array}$ \\
\hline GUESS_FIRST & $\begin{array}{l}0.533 \\
(0.006)\end{array}$ & $\begin{array}{l}-0.443 \\
(0.017)\end{array}$ & $\begin{array}{l}-0.09 \\
(0.147)\end{array}$ \\
\hline GUESS_LAST & $\begin{array}{l}0.554 \\
(0.030)\end{array}$ & $\begin{array}{l}-0.498 \\
(0.045)\end{array}$ & $\begin{array}{l}-0.056 \\
(0.198)\end{array}$ \\
\hline WELFARE_STATE & $\begin{array}{l}-0.805 \\
(0.003)\end{array}$ & $\begin{array}{l}0.633 \\
(0.031)\end{array}$ & $\begin{array}{l}0.172 \\
(0.120)\end{array}$ \\
\hline STATUS_IMPROVEMENT & $\begin{array}{l}-0.074 \\
(0.539)\end{array}$ & $\begin{array}{l}0.059 \\
(0.545)\end{array}$ & $\begin{array}{l}0.016 \\
(0.566)\end{array}$ \\
\hline INTRINSIC_SUCCESS & $\begin{array}{l}-0.232 \\
(0.354)\end{array}$ & $\begin{array}{l}0.182 \\
(0.387)\end{array}$ & $\begin{array}{l}0.049 \\
(0.358)\end{array}$ \\
\hline CONTEXT_SUCCESS & $\begin{array}{l}-0.122 \\
(0.336)\end{array}$ & $\begin{array}{l}0.096 \\
(0.361)\end{array}$ & $\begin{array}{l}0.026 \\
(0.381)\end{array}$ \\
\hline FIRST_PROGRESSIVE & $\begin{array}{l}0.683 \\
(0.000)\end{array}$ & $\begin{array}{l}-0.568 \\
(0.002)\end{array}$ & $\begin{array}{l}-0.115 \\
(0.105)\end{array}$ \\
\hline FIRST_ACTFAIR & $\begin{array}{l}-0.201 \\
(0.390)\end{array}$ & $\begin{array}{l}0.155 \\
(0.397)\end{array}$ & $\begin{array}{l}-0.047 \\
(0.459)\end{array}$ \\
\hline $\begin{array}{l}\text { DEMOGRAPHIC CONTROL } \\
\mathrm{N} \\
\text { Log Likelihood } \\
\text { Prob > chi2 } \\
\text { ( } p \text { values in parentheses })\end{array}$ & \multicolumn{3}{|c|}{$\begin{array}{l}42 \\
-24.832047 \\
0.0003\end{array}$} \\
\hline
\end{tabular}

Table 14

\begin{tabular}{|c|c|c|c|c|}
\hline & & $\begin{array}{c}\text { Expected Middle class people who wrongly } \\
\text { predict their status under the VOI } \\
\text { condition }\end{array}$ \\
\hline & & \multicolumn{3}{|c|}{ Choice under the NO_VOI condition } \\
\hline \multirow{4}{*}{ Category } & Progressive & Proportional & $\begin{array}{c}\text { Actuarially } \\
\text { fair }\end{array}$ \\
\hline & $\begin{array}{c}\text { Rich } \\
(\mathbf{N}=\mathbf{2 5})\end{array}$ & 1 & 5 & 19 \\
\cline { 2 - 5 } & $\begin{array}{c}\text { Poor } \\
(\mathbf{N}=\mathbf{2 8})\end{array}$ & 19 & 3 & 6 \\
\hline
\end{tabular}

